\title{
REFLEXÕES SOBRE O ENSINO DE PORTUGUÊS COMO LÍNGUA DE ACOLHIMENTO PELO VIÉS DA PEDAGOGIA TRANSLANGUAGING
}

\author{
REFLEXIONES SOBRE LA ENSEÑANZA DE PORTUGUÉS COMO LENGUA \\ DE ACOGIDA POR EL SESGO DE LA PEDAGOGÍA TRANSLANGUAGING
}

\author{
REFLECTIONS ON THE TEACHING OF PORTUGUESE AS A WELCOMING \\ LANGUAGE THROUGH TRANSLANGUAGING PEDADOGY
}

\author{
Bruna Souza de OLIVEIRA ${ }^{1}$ \\ Mariana BULEGON ${ }^{2}$
}

\begin{abstract}
RESUMO: Este trabalho busca refletir acerca do ensino de Português como Língua de Acolhimento (PLAc), que se configura como ensino de Português como Língua Adicional (PLA) para pessoas em contextos de migração e refúgio. Buscamos como foco o ensino de PLAc em contextos de sala de aula multilíngue. Para tanto, levantamos alguns aspectos a serem pensados dentro desse contexto e relatamos uma prática realizada com alunos imigrantes haitianos inseridos em uma turma de EJA. A prática que relatamos está de acordo com a pedagogia translanguaging, tal como concebemos o ensino de PLAc de modo que proporcione a conscientização linguística, a interculturalidade e o empoderamento dos alunos dentro e fora de sala de aula.
\end{abstract}

PALAVRAS-CHAVE: Português como Língua de Acolhimento; Ensino de Jovens e Adultos; Multilinguismo; Pedagogia translanguaging.

RESUMEN: El trabajo tiene por objeto reflexionar acerca de la enseñanza de Portugués como Lengua de Acogida (PLAc), que se configura como enseñanza de Portugués como Lengua Adicional (PLA) para personas en contextos de migración y refugio. Buscamos como enfoque la enseñanza de PLAc en contextos de aula multilingüe. Para ello, señalamos algunos puntos a pensar dentro de este contexto y relatamos una práctica realizada con alumnos inmigrantes haitianos inseridos en un grupo de EJA. La práctica que relatamos está acorde con la pedagogía translanguaging, como comprendemos la enseñanza de PLAc de modo que proporcione la concientización lingüística, la interculturalidad y el empoderamiento de los alumnos dentro y fuera del aula.

\footnotetext{
${ }^{1}$ Universidade Federal do Rio Grande do Sul (UFRGS), Porto Alegre - RS - Brasil. Mestranda em Linguística Aplicada pelo Programa de Pós-Graduação em Letras (PPG LETRAS/UFRGS). Bolsista CNPq. ORCID: https://orcid.org/0000-0003-4811-1159. E-mail: brunasouoliveira@ gmail.com

${ }^{2}$ Universidade Federal do Rio Grande do Sul (UFRGS), Porto Alegre - RS - Brasil. Mestranda em Linguística Aplicada pelo Programa de Pós-Graduação em Letras (PPG LETRAS/UFRGS). Bolsista CAPES. ORCID: http://orcid.org/0000-0002-1064-1691. E-mail: bulegonm@gmail.com
} 
PALABRA-CLAVE: Portugués como Lengua de Acogida; Enseñanza de Jóvenes y Adultos; Multilinguismo; Pedagogía translanguaging.

ABSTRACT: This paper intends to reflect upon the teaching of Portuguese as a Welcoming Language (PLAc), which can be understood as the teaching of Portuguese as an Aditional Language (PLA) to immigrants and refugees. Our main focus is teaching PLAc in multilingual classroom contexts. Therefore, we discuss some aspects within this context and report a practice performed with Haitian immigrant students attending to an EJA classroom. The practice we report follows the line of translanguaging pedagogy, such that we conceive the teaching of PLAc so as to provide linguistic awareness interculturality and empowerment to students in and, if possible, outside the classroom.

KEYWORDS: Portuguese as a Welcoming Language; Education for Adults and Young People; Multiligualism; Translanguaging Pedagogy.

\section{Introdução}

O número de migrantes internacionais cresce exponencialmente e já representa 3,3\% da população global, o equivalente a 244 milhões de pessoas (ONU, 2018). Segundo o Alto Comissariado das Nações Unidas (ACNUR) ${ }^{3}$, a cada minuto, 25 pessoas entram em situação de refúgio no mundo. No Brasil, dados do relatório do Comitê Nacional para os Refugiados $\left(\right.$ CONARE) ${ }^{4}$ revelam que até 2018, 161,051 mil pessoas haviam realizado a solicitação de refúgio, sendo que, dentre estes, 11,231 mil pessoas tiveram seus vistos reconhecidos como de refugiados. Silva (2017) infere sobre a complexidade das migrações no atual momento global, como sendo "a sua dispersão mais ampla pelo mundo, em diferentes escalas, tanto regional quanto internacional, assim como o prolongamento de sua situação nesse processo" (SILVA, 2017, p. 167). Desse modo, o Brasil se enquadra nesse cenário como um dos países que interpretava a pauta da migração com determinada transitoriedade e que, nesta conjuntura, assume a condição de país acolhedor de um contínuo fluxo de migrantes, mas que carece substancialmente de políticas públicas que deem conta dessa reorganização social.

Uma das questões emergentes que surgem para essa nova configuração da sociedade brasileira com a presença de imigrantes e refugiados é a necessidade de

${ }^{3}$ Disponível em: http://atue.acnur.org/. Acesso em: 10 ago. 2019.

4 Disponível em: https://www.acnur.org/portugues/dados-sobre-refugio/dados-sobre-refugio-no-brasil/. Acesso em: 10 ago. 2019. 
criação de políticas públicas que garantam o acesso desses imigrantes e refugiados à educação, ao aprendizado da Língua Portuguesa e à inserção no mercado de trabalho. Com a obtenção do visto de refugiado, ou do visto humanitário ${ }^{5}$, os imigrantes têm direito à educação, saúde e trabalho no Brasil. Porém, a Lei do Refúgio (BRASIL, 1951) não garante acessibilidade ao aprendizado do português, cabendo a eles buscar desenvolver a aprendizagem do idioma para a inserção nas diversas esferas da sociedade brasileira.

Nesse sentido, refletimos sobre o ensino de Português como Língua de Acolhimento (PLAc) ${ }^{6}$, termo difundido por Grosso (2010) em Portugal, que remete ao ensino de Português como Língua Adicional (PLA) ${ }^{7}$ para imigrantes e refugiados. Pesquisadores e professores brasileiros (ANUNCIAÇÃO, 2016; LOPEZ, 2017; RUANO e CURSINO 2019; SOARES e TIRLONI, 2019; BULEGON e SOARES, 2019; BULLA et al, 2019) consideram que o ensino de PLAc não deve ser assumido como um ensino de língua assimilacionista da língua e da cultura-alvo, devendo sempre levar em conta também a cultura e a intersubjetividade dos estudantes imigrantes e refugiados. Neste trabalho, buscamos propor que também seja valorizada a língua materna do aluno para a aprendizagem da língua adicional.

Até o presente momento, podemos observar que o ensino de PLAc para jovens e adultos tem sido promovido por projetos vinculados à Instituições de Ensino Superior $(\mathrm{IES})^{8}$, ou por ou cursos organizados pela sociedade civil, como o caso de ONGs, onde os professores são majoritariamente voluntários, muitas vezes sem formação em Letras. Há também a reserva de vagas para alunos imigrantes e refugiados na escola básica regular, na Educação de Jovens e Adultos (EJA), e em algumas IES, como o caso da UFRGS e da UFPR, que efetuam políticas de acesso ao ensino superior por meio de processos seletivos específicos para esse público (OLIVEIRA, 2019).

${ }^{5}$ Conferido a imigrantes haitianos e sírios, conforme Resolução Normativa n ${ }^{\circ}$ 97, de 2012, e Resolução Normativa ${ }^{\circ} 17$ de 2013.

${ }^{6}$ Grosso (2010) define PLAc como "um conceito que geralmente está ligado ao contexto de acolhimento, expressão que se associa ao contexto migratório, mas que, sendo geralmente um público adulto, aprende o português não como língua veicular de outras disciplinas, mas por diferentes necessidades contextuais, ligadas muitas vezes à resolução de questões de sobrevivência urgentes, em que a língua de acolhimento tem de ser o elo de interação afetivo (bidirecional) como primeira forma de integração (na imersão linguística) para uma plena cidadania democrática." (p. 74).

${ }^{7}$ Conforme Schlatter e Garcez (2009), o termo Língua Adicional remete ao acréscimo no repertório uma língua que acrescenta, além do idioma e seus conhecimentos linguísticos, um conhecimento que vai além da ideia de fronteiras entre estados e nações.

${ }^{8}$ Podemos citar como exemplo os casos da UFRGS, PUCRS, UFPR, UFFS, UFMG, UNIR e UFRR (FERREIRA et al, 2019). 
Cabe destacar alguns desafios que são comuns a todos os contextos de ensino de PLAc, quais sejam: i) a carência de materiais didáticos específicos para esta prática de ensino que possam dar conta das demandas e especificidades deste público; ii) a dificuldade de deslocamento dos alunos até os locais dos cursos oferecidos; iii) a baixa frequência dos alunos nas salas de aula. Para mais, também vemos como desafio um ensino de PLAc que valorize a cultura e o repertório linguístico dos alunos, de modo que possa não apenas ensinar uma língua para viver no Brasil, mas que busque promover empoderamento através de processos identitários com o ensino de PLAc.

Neste trabalho, colocamos em foco o ensino de PLAc para imigrantes e refugiados jovens e adultos, na escola básica regular, que, no caso de Porto Alegre, ocorre em escolas que oferecem a educação para jovens e adultos (EJA) da rede municipal da cidade (BULLA et al., 2017; BULLA et al., 2019;). A matrícula em aulas da EJA torna-se uma oportunidade para imigrantes e refugiados interagirem em português. Além do contato com a língua, esta modalidade de ensino também possibilita a obtenção de um diploma de conclusão da etapa cursada no Brasil, oportunizando a busca pela inserção no mercado de trabalho (BULLA et al., 2017). Trata-se, portanto, de um contexto de sala de aula multilíngue, tendo em vista que a convivência de alunos brasileiros, imigrantes e refugiados é facilitada.

O professor das turmas de EJA, nesse caso, se depara com o desafio de pensar em aulas que possam dar conta das demandas dessas turmas tão diversas. Uma possibilidade para trabalhar nesse contexto de ensino, de modo a incluir todos os alunos e suas culturas, é a perspectiva da pedagogia translanguaging (GARCÍA, 2009) que propõe práticas pedagógicas de valorização do repertório linguístico do aluno com o objetivo de auxiliar o aluno na aprendizagem da língua alvo. O professor, nesse sentido, pode exercer a função de "um gestor do desenvolvimento das competências plurilíngues e na promoção de uma consciência plural" (ALTHOFFEN; MORELLO, 2013, p. 23), à medida que estará criando espaços na sala de aula para que alunos percebam e utilizem todo o seu repertório linguístico.

Diante do exposto, este trabalho se propõe a apresentar e discutir o conceito de Português como Língua de acolhimento, seus desafios e especificidades, pensando no contexto escolar que acolhe estudantes imigrantes e refugiados na modalidade EJA. Após essas considerações, tecemos comentários acerca da pedagogia translanguaging, buscando entender de que forma podemos nos valer dela para promover trocas interculturais e oportunizar o (re)conhecimento linguístico de todos os alunos presentes 
na sala de aula. Para ilustrar essa reflexão, relataremos e discutiremos uma prática docente realizada em uma turma de EJA de uma escola de Porto Alegre com 10 alunos haitianos, refletindo sobre como ela pode ser realizada em contextos multilíngues. Desejamos que a leitura possa contribuir de alguma forma com a prática de professores que vivenciam essa realidade.

\section{Português como Língua de Acolhimento (PLAc)}

Embora o Brasil seja um país plurilíngue, com mais de 220 línguas indígenas e mais de 51 línguas advindas de processos de migração (ALTENHOFEN; MORELLO, 2013; SEIFFERT, 2009;), permanece no imaginário da sociedade brasileira o mito de que vivemos em um país monolíngue. Com a chegada dos novos fluxos migratórios desde 2010, mais línguas têm permeado a realidade de muitas cidades brasileiras, oriundas de países como Síria, República Democrática do Congo, Paquistão, Palestina, Angola, Venezuela, Cuba, Angola, Haiti, Síria (AMADO 2013; OLIVEIRA 2017;), enriquecendo ainda mais o repertório linguístico da sociedade brasileira. Somados a essa pluralidade de línguas que abrange a realidade de muitas regiões do país, vivemos em uma sociedade globalizada onde o acesso à Língua Inglesa e Espanhola tem sido mais valorizado e feito parte da realidade da maioria da população.

Nos debruçamos acerca do ensino de PLAc como um ensino de língua aditivo em sala de aula multilíngue, tendo em vista que não só em contexto de EJA estão presentes alunos de diferentes nacionalidades e falantes de diferentes idiomas, mas em todas as esferas que se propõem a trabalhar essa modalidade de ensino, seja em cursos oferecidos por projetos vinculados a IES ou cursos oferecidos por ONGs. Em conformidade com Ruano e Cursino (2019) “quando falamos em acolhimento, falamos do ensino do idioma para um público adulto, recém-imerso numa realidade linguísticocultural não vivenciada antes" (p. 45).

Oliveira (2019) aponta que o ensino de PLAc é diferente do ensino de PLA por não se tratar, geralmente, de uma escolha do estudante, uma vez que, em situação de migração forçada, se veem na necessidade de aprender o idioma para sua sobrevivência no país. Segundo a autora, "aprender português se torna quase imprescindível para se obter um emprego, estabelecer contatos pessoais e sociais, acessar e transitar entre 
instituições desempenhar atividades no cotidiano e, até mesmo, defender-se de potenciais abusos e desrespeito a direitos" (OLIVEIRA, 2019, p. 67).

Bulegon e Soares (2019) sugerem reflexões acerca de um ensino de PLAc que possa promover agentividade, fazendo um convite a professores e pesquisadores da área para refletir acerca do acolhimento em língua portuguesa e do ensino de PLAc que sirva não só ao ensino da língua, mas que também dê voz e empoderamento a estes estudantes. Tendo em vista as condições em que estão inseridos os imigrantes e refugiados no Brasil, as autoras consideram "que uma forma de resistir e promover agenciamentos é fazer com que nossos alunos de PLAc aprendam português não apenas para servir ao modelo neoliberal em que estamos inseridos, mas para reivindicar junto conosco uma sociedade mais justa e menos segregada. " (p. 16).

Apreciadas algumas considerações que expõem o estado da arte do ensino de PLAc, buscamos relacionar tais especificidades em uma prática realizada em uma turma de imigrantes matriculados no EJA de uma escola de Porto Alegre, cujo contexto multilíngue permitiu proporcionar um ensino-aprendizagem por meio de uma proposta em sala de aula a partir da pedagogia translanguaging (GARCIA, 2009). Na próxima seção, discutimos com mais profundidade as especificidades de um contexto de sala de aula multilíngue e multicultural.

\section{Sala de aula multilíngue e multicultural}

De acordo com Zimmer, Finger e Scherer (2008), sujeitos bi/multilíngues podem ser compreendidos como "pessoas com diferentes graus de competência nas línguas que usam. Assim, os bilíngues e multilíngues podem ter mais ou menos fluência numa língua do que em outra; podem ter desempenhos diferentes nas línguas em função do contexto de uso e do propósito comunicativo" (p.5). As autoras complementam também a ideia de não linearidade da competência bi/multilíngue, pois ela varia através do tempo de vida de cada pessoa, dependendo de fatores externos e internos. Em outra definição de falantes bilíngues/ multilíngues, Edwards (2006), argumenta que "Todo mundo é bilíngue. Ou seja, não há ninguém no mundo (nenhum adulto) que não saiba pelo menos algumas palavras em línguas que não a materna” (p. 7).

Frente à essa perspectiva, qualquer contexto de aula de língua adicional implica em um contexto de aula multilíngue, ou seja, mais de uma língua permeia o ensino de 
língua adicional diretamente, pois sempre estaremos em contato com a língua materna e a língua-alvo. Quando tratamos de entender o contexto de salas de aulas com alunos imigrantes e refugiados e alunos brasileiros, inseridos em turmas de EJA, se faz necessário compreender a existência de sujeitos com diversidade de repertórios linguísticos. Aulas pensadas para esse contexto implicam, portanto, em não tratar somente de enfocar o aprendizado da língua-alvo, mas essencialmente preparar os alunos para serem formados com uma "competência cultural e plurilíngue" (SPINASSÉ; KAFER, 2017, p. 395). Para mais, também deve ser valorizada a cultura do aluno imigrante, de modo que a construção da aprendizagem da língua e da culturaalvo possa ser construída a partir dela, e não através de seu apagamento (RUANO; CURSINO, 2019).

Dessa forma, busca-se incluir as línguas dos alunos dentro da sala de aula, considerando a importância de todas as línguas dentro do processo de aprendizado de cada um, reconhecendo a realidade linguística da turma como uma oportunidade de promover novos aprendizados sobre a turma e a sociedade (SPINASSÉ; KAFER, 2017).

A aula das turmas de EJA com a presença de imigrantes e refugiados podem se tornar, dessa maneira, um lugar de trocas interculturais e de reconhecimento de suas línguas e seus processos de aprendizado. Maher (2007) e Lopez (2017) discorrem sobre o conceito de interculturalidade pensado na aula de língua, entendendo-a como como prática docente de respeito e valorização à diferença dos diversos grupos culturais, enfocando na importância de se propor “o caráter dinâmico, híbrido, não-consensual e não hierarquizáveis das culturas" (MAHER, 2007, p. 264). Para Lopez (2017), em aulas pensadas para o contexto de imigração e refúgio, a prática da promoção da interculturalidade objetiva e direciona a valorização da cultura dos alunos que em muitos casos se encontram excluídos da sociedade acolhedora.

Incluir a interculturalidade dos alunos dentro da sala de aula também oportuniza o empoderamento e agentividade (GARCÍA, 2009; BULEGON; SOARES, 2019) de sua voz e de sua forma de perceber o mundo, a mudança de visão dos alunos sobre a escola que eles frequentam, um maior sentimento de pertencimento e consequentemente mais aprendizado. Em contextos que envolvem alunos imigrantes e refugiados, trazer a língua dos alunos para dentro da aula, abre um espaço importante para um maior acolhimento no país receptor. 


\section{Reflexões acerca da pedagogia translanguaging como proposta didática para contextos multilíngues}

Entendemos que a pedagogia translanguaging dialoga com a perspectiva teórica de contextos de ensino multilíngue que apreciamos na seção anterior, bem como com a proposta de prática que exporemos mais adiante em nosso trabalho. Além disso, também nos alinhamos ao ensino de PLAc que busque promover o empoderamento dos alunos imigrantes. Por conta disso, compreendemos a pedagogia translanguaging como uma forma de valorizar a língua e cultura do aluno em sala de aula, a fim de os alunos se sintam escutados e valorizados pelo menos na sala de aula e que promovam sua agentividade (BULEGON; SOARES, 2019) dentro e fora dela.

A pesquisadora e professora cubana Ofélia Garcia, com um extenso registro de publicações acerca de pedagogias bilíngues, em sua obra intitulada Bilingual Education in 21st Century: A global perspective busca olhar para línguas minoritárias e ensino de línguas em contexto de migração, majoritariamente em escolas de diversos contextos, nos Estados Unidos. Segundo a autora,

As escolas precisam encontrar maneiras de garantir que todos os alunos, e não apenas aqueles cujas práticas linguísticas estejam alinhadas com as utilizadas na escola, compreendam conteúdo e texto desafiadores. A pedagogia translanguaging permite que os educadores ofereçam oportunidades mais igualitárias para os alunos se envolverem com materiais complexos, independentemente de suas práticas linguísticas. Dessa forma, a prática translanguaging na escola está inextricavelmente ligada à justiça social. (GARCIA, 2009, p. 8 , tradução nossa). ${ }^{9}$

No primeiro capítulo do livro supramencionado, a autora afirma que, muitas vezes, os professores de inglês das escolas americanas não permitem que seus alunos latinos falem espanhol em suas aulas, apenas inglês. A autora aponta que o resultado disso é o silenciamento de sua cultura latina, fazendo com que os alunos falem suas línguas e exerçam suas culturas somente em suas comunidades de práticas fora da escola. Como solução, a autora sugere que "alavancar o translanguaging de maneira interpessoal e intrapessoal pode ajudar os alunos bilíngues a superar esse silêncio e a se

\footnotetext{
${ }^{9}$ Schools need to find ways of ensuring that all students, not just who those whose language practices align with those used in school, understand challenging content and text. Translanguaging enables educators to more equitably provide opportunities for students to engage with complex material, regardless of language practices. In this way, translanguaging at school is inextricably linked with social justice.
} 
envolver e entender conteúdo e textos complexos" (GARCIA, 2009, p. 8, tradução nossa).

Garcia (2009), ao discutir e promover uma pedagogia translanguaging, compreende a noção de repertórios linguísticos, ou seja, que as línguas não são separadas entre si dentro de cada sujeito, mas integradas. Cada um de nós possui um repertório linguístico, onde cada língua que aprendemos se associa a outras línguas, constituindo juntas a nossa capacidade de expressão e nos constituindo enquanto sujeitos. Usamos nosso repertório de diversas formas, ajustando-o de acordo com nossos interlocutores. Dessa forma, todo o repertório linguístico está ativo em cada sujeito, de modo que podemos utilizar o repertório linguístico completo dos alunos para que eles possam desenvolver seu aprendizado na nova língua nova.

Destarte, consideramos que a promoção de práticas translanguaging em aulas de PLAc inseridas em contextos multilíngues pode oportunizar um ensino de língua de acolhimento direcionado ao dessilenciamento e empoderamento dos alunos, trazendo suas vozes para a sala de aula. Para dar conta desse conceito, relatamos uma prática realizada com uma turma de alunos haitianos, matriculados no EJA de uma escola de Porto Alegre, onde foi possível realizar uma atividade translanguaging, aproveitando o contexto multilíngue.

Com base nas considerações feitas neste trabalho sobre contextos multilíngue e pedagogia translanguaging, podemos ressaltar alguns pressupostos que podem auxiliar professores no planejamento de tarefas, sequências didáticas e projetos em salas de aulas que tenham a presença de alunos imigrantes e refugiados. Esses pressupostos destacados no quadro a seguir são os pressupostos que discutimos na prática realizada com os alunos haitianos a ser apresentada na seção posterior.

Quadro 1: Pressupostos para planejamento de tarefas, sequências didáticas e projetos de ensino

\begin{tabular}{|c|c|}
\hline $\begin{array}{c}\text { Conscientização linguística } \\
\text { e valorizaça do repertório } \\
\text { linguístico do aluno; }\end{array}$ & $\begin{array}{c}\text { Promoção de consciência sobre as línguas existentes na turma ou } \\
\text { comunidade; Reconhecimentos de aspectos parecidos e diferentes entre as línguas, } \\
\text { que podem gerar autonomia do processo de aprendizagem das línguas; Inclusão } \\
\text { do repertório linguístico do aluno nas atividades da sala de aula; }\end{array}$ \\
\hline Interculturalidade & $\begin{array}{c}\text { Reconhecimento das diferenças e semelhanças culturais existentes na } \\
\text { turma e no mundo; }\end{array}$ \\
\hline Empoderamento & $\begin{array}{c}\text { Através da inclusão das línguas existentes na turma ou comunidade, a } \\
\text { voz que seus falantes recebem dentro da sala de aula, na escola e na comunidade; }\end{array}$ \\
\hline
\end{tabular}

Fonte: elaborado pelas autoras 


\section{Proposta de prática translanguaging para uma aula de PLAc}

As turmas de EJA apresentam características próprias por se tratarem de alunos jovens e adultos, com uma diversidade de experiências adquiridas ao longo da vida de alunos que retomam seus estudos depois da idade regular escolar (FONSECA, 2002). Os alunos imigrantes e refugiados que buscam o aprendizado do português, por sua vez, também carregam suas particularidades a partir de suas demandas. Uma característica que tanto as turmas de PLAc quanto de EJA carregam em comum são as frequências não regulares nas aulas (ANDRIGHETTI, PERNA; PORTO, 2017; BULLA et al., 2017; OLIVEIRA, 2017;).

Desse modo, esta proposta de prática translanguaging, materializada em formato de uma sequência didática, busca se adequar à necessidade contextual, propondo uma aula que aconteça em um encontro, ou seja, começando e terminando no mesmo dia. A dinâmica da sequência didática a ser apresentada busca possibilitar a interação dos alunos, baseada em uma perspectiva da linguagem dialógica, translanguaging, que compreende o uso da língua como ação social (CLARK, 2000; GARCIA, 2009; BAKHTIN, 2003;).

É importante elucidar as definições de tarefas e atividades considerados ao longo deste artigo. Por tarefa pedagógica entende-se como "um convite para que ações sejam realizadas conforme uma sugestão de enquadramento de atividades futuras e sustentadas por objetivos educacionais" (BULLA;LEMOS; SCHLATTER, 2012, p. 108). Por sua vez, entende-se por atividades pedagógicas as ações a serem realizadas através das tarefas.

A sequência didática foi proposta para uma aula introdutória do semestre/ano escolar, com alunos haitianos e professores brasileiros, abordando apresentação pessoal dos alunos e professores. O objetivo era motivar a apresentação dos alunos em todas as línguas faladas naquela sala de aula, que nesse caso eram o crioulo haitiano, francês e português, para, a partir desse exercício, dar continuidade com a gravação de um vídeo para compartilhamento na internet.

Essa prática didática foi realizada em uma turma onde todos os alunos eram da mesma nacionalidade haitiana, mas com a representatividade de mais de uma língua (crioulo haitiano e francês), além do português que era a língua alvo dos alunos. Nossa proposta de discutir essa tarefa nesse artigo tem como enfoque elucidar que, em contextos onde alunos imigrantes e refugiados de diversas nacionalidades dividem a 
mesma sala de aula com colegas brasileiros, propostas como essa podem se alinhar ainda mais à pedagogia translanguaging para promover: i) A conscientização linguística e valorização do repertório linguístico dos alunos ii) Promoção da interculturalidade na sala de aula; iii) Promoção do empoderamento dos alunos.

Para apresentarmos detalhadamente a proposição de sequência didática e as especificidades das tarefas desenvolvidas, elaboramos os dois quadros subsequentes. No Quadro 2, explicitamos os objetivos, gêneros estruturantes, materiais necessários e a sugestão de etapa do semestre/ano letivo que essa sequência didática pode ser aplicada. No Quadro3, descrevemos cada etapa da sequência didática proposta.

Quadro 2: Descrevendo a proposta de sequência didática

Objetivos: Proporcionar que os alunos interajam um pouco com a língua dos colegas e conheçam a diversidade linguística que existe em sua sala de aula; possibilitar que os alunos aprendam a se apresentar nas línguas dos colegas e na língua alvo que neste caso é o português;

Gênero Estruturante: Apresentação pessoal; Vídeo para ser compartilhado/ postado na internet com o uso da câmera do celular (se os alunos não possuírem celular, pode ser utilizado o celular da professora);

Materiais necessários: Papel/ Caneta/ Quadro/ Material para escrever no quadro/ Celulares do aluno ou da professora: Smartphone/ Internet

Sugestão de etapa do semestre/ano letivo: Aula inicial;

Fonte: elaborado pelas autoras

Quadro 3: Descrição dos momentos da sequência didática e tarefas

Momento 1 O professor pergunta aos alunos as línguas que eles falam. Os nomes dos alunos são escritos no quadro, juntamente com as línguas faladas por eles.

Sugestão: trabalhar com o mapa mundi, identificando no mapa onde os países dos colegas se localizam, assim como localização de Porto Alegre.

Momento 2 O professor propõe a tarefa: Cada colega deve encontrar um colega que não fale sua língua para trabalharem juntos. Pode escrever a tarefa no quadro, ou organizar a turma com alunos de lugares diferentes.

Quando os alunos se agrupam, devem escrever as frases de apresentação pessoal, em Língua Portuguesa primeiramente, juntos.

Momento 3 O professor pergunta aos alunos as frases necessárias para se apresentar em português. As escreve no quadro em uma grande tabela, deixando colunas para as frases equivalentes nas outras línguas. Aceita as sugestões de frases dos alunos, as escreve e pode também sugerir outras frases.

Momento 4 A partir disso, cada grupo de alunos escreve com seus pares como se apresentar nas outras línguas diferentes da Língua Portuguesa, seguindo os modelos de frases já escritos no quadro.

Momento 5 O professor escreve no quadro as frases em outras línguas. Assim que os alunos compartilham seus conhecimentos linguísticos, eles devem fazer o exercício de se apresentar nessa nova língua para a turma.

Momento 6 Depois dessa rodada, os alunos gravam os vídeos, com seus celulares ou celulares do professor (Se possível) (professores), apresentando-se na língua diferente da sua língua materna.

Momento 7 Os alunos assistem aos vídeos gravados pelos colegas em um momento que pode ser 


\begin{tabular}{|l|l|}
\hline (Se possível) & compartilhado virtualmente ou não. \\
\hline Momento 8 & $\begin{array}{l}\text { O professor discute com os alunos sobre o que eles encontram de diferenças e similaridades } \\
\text { nessas línguas. Os alunos observam olhando para a grande tabela do quadro, aspectos } \\
\text { linguísticos como pronomes, verbos, adjetivos. }\end{array}$ \\
\hline Momento 9 & $\begin{array}{l}\text { Como tarefa de casa, é pedido que os alunos compartilhem os vídeos para que outras pessoas } \\
\text { possam aprender um pouco sobre essa nova língua aprendida. No caso dos imigrantes e } \\
\text { refugiados sobre a aprendizagem do português, no caso dos brasileiros, sobre essa(s) nova(s) } \\
\text { língua(s). }\end{array}$ \\
\hline
\end{tabular}

Fonte: Elaborado pelas autoras

A sequência didática apresentada buscou valorizar a língua e a cultura presentes em uma sala de aula em contexto multilíngue. Dessa forma, foi possível promover a interação entre os alunos, o (re)conhecimento de suas línguas a promoção de processos indenitários, valorizando conhecimentos prévios e construindo um ambiente de aprendizagem colaborativa a partir disso. Ao aprender sobre as línguas existentes na sala de aula e aprender sobre como se expressar nessa língua diferente da sua, exercitase a conscientização linguística que abarca a sala de aula pautada na pedadogia translanguaging. Essa conscientização também acontece no momento em que o professor propõe perguntas de análise sobre semelhanças e diferenças nos aspectos linguísticos entre as línguas, e, desta forma, sobre a análise consciente que cada um tem sobre sua língua e sobre o aprendizado de línguas. Propostas como estas em sala de aula promovem a valorização dos repertórios linguísticos dos alunos, possibilitando que a sala de aula, mesmo que enfocando o aprendizado da Língua Portuguesa, também seja um espaço para que as línguas que os constituem enquanto sujeitos socioculturais sejam valorizadas (GARCÍA, 2009; SPINASSÉ; KAFER, 2017;).

Práticas que trazem a forma de se expressar dos alunos e seus repertórios linguísticos para dentro das propostas de aprendizagem são promotores da interculturalidade dentro da sala de aula, de modo a utilizar a consciência de diversidade cultural e plurilinguismo existente na sociedade como um motor do aprendizado (MAHER, 2007; LOPEZ, 2016;). Quando pensamos em contextos de ensino onde alunos imigrantes e refugiados estão presentes, negligenciar a interculturalidade evidente na sala de aula contribui com o apagamento da identidade do aluno.

A proposta didática ressalta também a agentividade (BULEGON; SOARES, 2019;) dos alunos através da oportunidade de todos se colocarem como professores de suas línguas e alunos das línguas do outro. Em contexto de ensino e aprendizagem de língua com alunos em situação de imigração e refúgio, uso da pedagogia 
translanguaging pode ser um aspecto chave para que o aprendizado do aluno aconteça proporcionando o acolhimento através da troca de saberes linguísticos e culturais.

\section{Considerações finais}

Pensar no ensino de línguas adicionais implica em considerar que cada sala de aula pode proporcionar um contexto multilíngue, tendo em vista que sempre vai existir a língua do aluno e a língua que está sendo aprendida. Se pensarmos em contextos de ensino que recebem alunos imigrantes e refugiados, considerar todo o repertório linguístico dos alunos, bem como sua história e cultura, são aspectos chaves para promover uma aula inclusiva. Uma proposta didática pensada para contextos de imigração e refúgio, orientada para reconhecer a língua e cultura do aluno, reforça o não apagamento de sua identidade e é decisivo para um ensino-aprendizagem intercultural.

Com o aumento exponencial da presença de alunos imigrantes e refugiados nos contextos de ensino brasileiro, a proposta de pedagogia translanguaging (GARCÍA, 2009), atrelada a pressupostos de ensino que promovam a conscientização linguística dos alunos (SPINASSÉ; KAFER, 2017), a troca intercultural (MAHER, 2007; LOPEZ, 2016;) e a agentividade de discentes através da mobilização de suas línguas em sala de aula (BULEGON; SOARES, 2019), são propostas que consideramos menos engessadas no ensino da língua do país que acolhe, diminuindo o caráter colonizador do ensino e valorizando as subjetividades do alunado. O professor se configura, neste contexto, como um promotor desse espaço capaz de abranger na sua aula o ensino de língua atrelado ao ensino de cultura. As tarefas, nesse sentido, direcionam os alunos a discutir e compreender a pluralidade sociocultural. O desafio se estabelece em compreender uma turma tão plural, com demandas tão diversas e desenvolver aulas que atendam e entendam essas demandas.

É importante ressaltar que a proposta didática apresentada neste artigo está estruturada a nível teórico da pedagogia translanguaging, e que as demandas práticas abrangem tantas outras diversidades específicas não desenvolvidas neste estudo. Uma questão pertinente referente a esse contexto de ensino se refere à diversidade de níveis de letramentos dos alunos, tanto da EJA, quanto imigrantes e refugiados, deixadas em aberto. 
Como professoras e pesquisadoras de PLAc, entendemos que nosso alunado contribui com nossas práticas ao mobilizar todo seu repertório cultural e linguístico, proporcionando muita aprendizagem a nós e a seus colegas a partir das trocas promovidas em sala de aula. O Brasil é um país de imigrantes, desejamos que a pluralidade cultural e linguística de todos os imigrantes desse país nunca deixe ser valorizada, escutada e que sempre encontre espaços dentro e fora de sala de aula e que, principalmente, através da agentividade e do empoderamento, nossos novos imigrantes possam sempre encontrar e abrir espaços.

\section{REFERÊNCIAS}

ALTENHOFEN, C. V.; MORELLO, R. Rumos e perspectivas das políticas linguísticas para línguas minoritárias no Brasil: entre a perda e o inventário de línguas. In: Encontro internacional de investigadores de políticas linguísticas, 6., Porto Alegre, 23 a 25 de setembro de 2013. Anais de textos completos do Encontro Internacional de Investigadores de Políticas Linguísticas. Porto Alegre: UFGRS, 2013. Organizado por Nalú Forenzeana.

AMADO, R. S. O português como língua de acolhimento para refugiados. Revista da SIPLE. Brasília, n. 2, ano 4, out. 2013. Disponível em:

http://www.siple.org.br/index.php?option=com_content\&view=article\&id=309:0ensino-de-portugues-como-lingua-de-acolhimento-para-refugiados \&catid=70:edicao7\&Itemid=113. Acesso em: 11 ago. 2019.

ANDRIGHETTI, G. H.; PERNA, C. B. L., PORTO, M. M. Português como língua de acolhimento na Lomba do Pinheiro: relatos de práticas pedagógicas. Belt: Brazilian English Language Journal. Porto Alegre, v. 8, n. 2, p. 191-208, jul./dez., 2017,

BAKHTIN, M. Estética da criação verbal. São Paulo: Martins Fontes, 2003.

BULEGON, M.; SOARES, L. F. Impactos sociais dos novos fluxos migratórios e políticas linguísticas no Brasil: o ensino de Português como Língua de Acolhimento (PLAc). Revista on line de Política e Gestão Educacional, Araraquara, v. 23, n. 3, p. 368-655, set./dez., 2019

BULLA, G. S.; LAGES e SILVA, R.; OLIVEIRA, B. S.; CONCEIÇÃO, J. V. Português para imigrantes e refugiados na UFRGS: Ações de política linguística e educacional. In: FERREIRA L. C.; PERNA, C.; Gualda, R.; LEURQUIN, E. V. L. F. (Orgs.). Língua de acolhimento: experiências no brasil e no mundo. Belo Horizonte: Mosaico Produção Editorial. 2019.

BULLA, G. S.; LAGES E SILVA, R.; LUCENA, J. C.; SILVA, L. P. Imigração, refúgio e políticas linguísticas no Brasil: Reflexões sobre escola plurilíngue e formação 
de professores a partir de uma prática educacional com estudantes haitianos. Revista Organon, v. 32, n. 62, p.114, 2017.

BULLA, G. S.; LEMOS, F. C.; SCHLATTER, M. Análise de material didático para o ensino de línguas adicionais a distância: reflexões e orientações para o design de tarefas pedagógicas. Revista Horizonte de Linguística Aplicada, v. 11, p.103-135, 2012.

CLARK, Herbert Herb. O uso da linguagem. In: Cadernos de Tradução, Porto Alegre, no 9, p. 55-80, jan./mar., 2000.

EDWARDS, John. Foundations of Bilingualism. BHATIA, T.K.; RITCHIE, W. C. (Eds.) The Handbook of Bilingualism. Oxford: Blackwell, 2006, p. 7 - 31.

FONSECA, M. C. F. R. Educação de jovens e adultos, especificidades, desafios, contribuições. Belo Horizonte: Autêntica, 2002.

GARCÍA, O. Bilingual Education in the 21st Century: a global perspective. MA: Wiley/Blackwell, 2009.

GROSSO, Maria José dos Reis. Língua de acolhimento, língua de integração.

Horizontes de Linguística Aplicada, v. 9, n. 2, p. 61-77, 2010.

LOPEZ, A.P.A. Subsídios para o planejamento de cursos de Português como Língua de Acolhimento para Imigrantes Deslocados Forçados no Brasil. Dissertação de Mestrado. Universidade Federal de Minas Gerais, 2017.

MAHER, T. M. A. A educação do entorno para a interculturalidade e o plurilinguísmo. In: KLEIMAN, A. B.; CAVALCANTI, M. C. (orgs.) Linguística Aplicada: suas faces e interfaces, Campinas: Mercado de Letras. 2007, p. 255-270.

OLIVEIRA, B. S. Construindo o ensino de português como língua de acolhimento: uma análise da apostila didática Pode Entrar. Trabalho de Conclusão de Curso Instituto de Letras: Universidade Federal do Rio Grande do Sul. Porto Alegre, 2017.

OLIVEIRA, D. A. A preparação de imigrantes para o ENEM: relatos de experiência docente. In: FERREIRA L. C.; PERNA, C.; Gualda, R.; LEURQUIN, E. V. L. F. (Orgs.). Língua de acolhimento: experiências no brasil e no mundo. Belo Horizonte: Mosaico Produção Editorial. 2019.

ORGANIZAÇÃO DAS NAÇÕES UNIDAS. International Organization for Migration. World Migration Report 2018. Genebra, Suíça: United Nations, 2018. Disponível em: https://publications.iom.int/system/files/pdf/wmr_2018_en.pdf. Acesso em: 10 ago. 2019.

PEREIRA, G. O Português como Língua de Acolhimento e interação: A busca pela autonomia por pessoas em situação de refúgio no Brasil. Cadernos de Pós-Graduação em Letras. São Paulo: Editora Mackenzie, v. 17. n.1, p. 118-134, jan./jun., 2017

RUANO, B. P.; CURSINO, C. Multiletramentos e o second space no ensinoaprendizagem de PLAc: da teoria à prática. In: FERREIRA L. C.; PERNA, C.; Gualda, 
R.; LEURQUIN, E. V. L. F. (Orgs.). Língua de acolhimento: experiências no brasil e no mundo. Belo Horizonte: Mosaico Produção Editorial. 2019.

SILVA, D. F. O fenômeno dos refugiados no mundo e o atual cenário complexo das migrações forçadas. Revista brasileira de Estudos Populacionais, Belo Horizonte, v.34, n.1, p.163-170, jan./abr. 2017.

SPINASSÉ. K. P.; KAFER, M. L. A conscientização linguística e a didática do multilinguismo em contextos de contato português - Hunsruckisch. Gragoatá, Niterói, v.22, n.42, p.393-415, jan-abr. 2017.

ZIMMER, M.; FINGER, I.; SCHERER, L. Do bilinguismo ao multilinguismo:

intersecções entre a psicolinguística e a neurolinguística. ReVEL. v. 6, n.11, ago. 2008.

\section{Como referenciar este artigo}

OLIVEIRA, Bruna Souza de; BULEGON, Mariana. Reflexões sobre o ensino de português como língua de acolhimento pelo viés da pedagogia translanguaging. Rev. EntreLínguas, Araraquara, v. 5, n. 2, p. 430-445, jul./dez. 2019. E-ISSN: 2447-3529. DOI: $10.29051 /$ el.v5i2.12958

Submetido em: 18/04/2019

Revisões requeridas: 03/05/2019

Aprovado em: 15/05/2019

Publicado em: 01/10/2019 